Parasitology

\section{cambridge.org/par}

\section{Research Article}

Cite this article: Brian JI, Aldridge DC (2020) An efficient photograph-based quantitative method for assessing castrating trematode parasites in bivalve molluscs. Parasitology 147, 1375-1380. https://doi.org/10.1017/ S0031182020001213

Received: 6 April 2020

Revised: 13 May 2020

Accepted: 8 July 2020

First published online: 30 July 2020

Key words:

Anodonta; bivalve; castration; cercariae; gonad; sporocyst

\section{Author for correspondence:}

Joshua I. Brian, E-mail: jib33@cam.ac.uk

\title{
An efficient photograph-based quantitative method for assessing castrating trematode parasites in bivalve molluscs
}

\section{Joshua I. Brian (1) and David C. Aldridge}

Aquatic Ecology Group, The David Attenborough Building, Department of Zoology, University of Cambridge, Cambridge CB2 3QZ, UK

\begin{abstract}
Parasitic castration of bivalves by trematodes is common, and may significantly reduce the reproductive capacity of ecologically important species. Understanding the intensity of infection is desirable, as it can indicate the time that has passed since infection, and influence the host's physiological and reproductive response. In addition, it is useful to know the developmental stage of the trematode, to understand trematode population trends and reproductive success. However, most existing methods (e.g. visually estimating the degree of infection) to assess intensity are approximate only and not reproducible. Here, we present a method to accurately quantify the percentage of bivalve gonad filled with digenean trematode tissue, based on small squashes of gonad tissue rapidly photographed under light microscopy. A maximum of 15 photographs is required to determine the percentage of the whole gonad occupied by trematodes with a minimum of $90 \%$ confidence, with smaller mussels requiring fewer. In addition, the stage of trematode infection can be assessed because full sporocysts, spent sporocysts and free cercariae are clearly distinguishable. Although variation exists in the distribution of trematodes in gonad tissue, and thus in the estimate of percentage of the gonad filled with trematodes, this method represents a marked improvement on current coarse assessments of infection which typically focus on binary presence/absence measures. This technique can be used to facilitate a more sophisticated understanding of host-parasite interactions in bivalves, and can inform the conservation and reproductive biology of environmentally crucial species.
\end{abstract}

(c) The Author(s), 2020. Published by Cambridge University Press. This is an Open Access article, distributed under the terms of the Creative Commons Attribution licence (http://creativecommons.org/licenses/by/4.0/), which permits unrestricted re-use, distribution, and reproduction in any medium, provided the original work is properly cited.

\section{CAMBRIDGE} UNIVERSITY PRESS

\section{Introduction}

Parasites face a classic trade-off between maximizing host exploitation and maintaining host longevity. A proposed evolutionary solution is castration of the host, which allows for complete redirection of host reproductive energy towards the parasite, while facilitating continued host survival (Baudoin, 1975; Lafferty and Kuris, 2009). Castration has a wide range of potential consequences on the host, including timing and success of reproduction, changes in distribution and overall energy allocation dynamics (Lafferty and Kuris, 2009), which can influence population-level reproductive output (Fredensborg et al., 2005). The types of consequences will depend on a range of factors including prevalence (what proportion of the population is infected), intensity (how many parasites, or how much parasite tissue, is present in a single individual) and infection biases such as age, sex and size. Parasitic castration is evident throughout the animal kingdom, but is particularly common in fish (e.g. Jobling and Tyler, 2003) and molluscs (e.g. Averbuj and Cremonte, 2010; Choubisa and Sheikh, 2013; Yee-Duarte et al., 2017).

The castration of molluscs, and in particular bivalves, is valuable and important to study for three reasons. First, bivalve population dynamics are of specific concern given they often fulfil important ecosystem engineering functions through filter-feeding, burrowing and providing a hard substrate to increase niche complexity (Sousa et al., 2009; Lopes-Lima et al., 2017). For example, through their filtering they can modify nearby water chemistry (Ninokawa et al., 2020), act as important nutrient cyclers (Atkinson et al., 2010) and form nutrient hotspots (Atkinson and Vaughn, 2015). As a result, their presence is associated with increased species richness in both marine and freshwater ecosystems (Aldridge et al., 2007; Borthagaray and Carranza, 2007; Chowdhury et al., 2016). Second, bivalves include some of the most globally imperilled taxa (Bogan, 1993; Smith et al., 2006; Lopes-Lima et al., 2018) and effective conservation programmes may benefit from understanding drivers of reduced fecundity. Third, bivalves are often found at high density, vary in possible resource availability to parasites in predictable and easily measurable ways (e.g. size, sex and gravidity) and are amenable to simple manipulation. These qualities make them a potential model system to study the individual, population-level and evolutionary effects of parasitic castration.

Digenean trematodes are common castrating parasites of bivalves, which utilize them as a first intermediate host (see Brian and Aldridge, 2019). Digeneans fill the gonad with asexually-reproducing sporocysts, rediae or both, which produce cercariae that are eventually released to infect the next host. This continued asexual growth eventually leads to castration of 
the bivalve host. These infections are chronic, and can last for life (Taskinen et al., 1997). Digeneans may also infect bivalves as a second intermediate host in the form of metacercariae. However, understanding the effects of digenean castration on bivalves is currently hindered by an inability to reliably quantify the level of infection, as the asexual branching growth of sporocysts means there are no specific 'individuals' that can be counted.

Evidence suggests that to understand the population-level effects of infection, quantitative data are required. For example, previous research indicates that being castrated (or not) and being infected (or not) should not be treated as binary variables. Taskinen and Valtonen (1995) demonstrated that $18.5 \%$ of mussels could still reproduce when infected with sporocyst tissue (though the level of infection for each mussel was not recorded). This suggests that mussels can still reproduce at some level of infection, and that sporocysts need to fill a certain proportion of the gonad before the bivalve is castrated. They further demonstrated that an increased quantity of sporocysts led to reduced number of host eggs being produced by females. Other studies have also suggested that an increased volume of trematode tissue can lead to more cercariae being produced (e.g. Hay et al., 2005; Thieltges et al., 2008), showing that infection intensity may have consequences for both host and parasite populations. However, most studies examining castrating parasites in bivalves use a small portion of the gonad, and either record infection status as a binary yes/no (e.g. Valderrama et al., 2004; Baudrimont et al., 2006; Zieritz and Aldridge, 2011; Marszewska and Cichy, 2015), or provide granular assessments of infection such as 'low' or 'high' (e.g. Taskinen et al., 1994, 1997; Yanovich, 2015). Binary records of infection may not be enough to capture the nuances of host-parasite dynamics, whereas the granular assessments of intensity are highly subjective and not reproducible, hampering efforts to compare population impacts between studies and locations. A better metric would potentially be a measure of intensity of infection, such as the percentage of the gonad filled with trematode tissue. Such an explicit quantitative measure is likely to correlate directly with the amount of tissue available for mussel and parasite reproduction. In addition, more comprehensive methods such as histology are time-consuming, require a high level of skill and may still lack objectivity unless a clear quantitative procedure is followed.

In this paper, we present a rapid photograph-based method to quantify the infection level within the gonad of a mollusc. It provides a reproducible measure of the percentage of the gonad filled, and can capture within-host trematode dynamics, by distinguishing between full sporocysts, spent sporocysts and free cercariae. Although this technique is exemplified with unionid mussels, we see it as applicable to all marine and freshwater bivalves.

\section{Methods}

\section{Study site and collection}

The duck mussel Anodonta anatina (Linnaeus 1758) is a common unionid with a pan-European distribution (Lopes-Lima et al., 2017). We collected samples of this mussel on a monthly basis between January and September from the Old West River at Stretham $\left(52.3343^{\circ} \mathrm{N}, 0.2243^{\circ} \mathrm{E}\right)$, part of the River Great Ouse system (UK). Exploratory dissections had revealed a proportion of these mussels to be infected with the digenean trematode Rhipidocotyle campanula (Dujardin 1845); this trematode produces cercariae from asexual sporocysts. We collected mussels by hand from near the bank, and transported back to the laboratory in $10 \mathrm{~L}$ buckets filled with river water. In the laboratory, we held mussels at $8^{\circ} \mathrm{C}$ under aeration, for a maximum of $72 \mathrm{~h}$ before assessments of trematode infection. Prior to assessment, we rinsed mussels under cold fresh water while holding the valves gently shut to remove any organisms on the shells, and measured maximum length to the nearest $0.5 \mathrm{~mm}$ with a Vernier callipers.

\section{Quantification of trematode infection}

We sacrificed and dissected mussels by inserting a scalpel between the valves and slicing the posterior and anterior adductor muscles. We gently removed the visceral mass by cutting the connective tissue at each end, and sliced it open using a single cut of a scalpel at the posterior end.

To confirm that a subsample of the gonad will approximate the true percentage of the gonad filled with trematode tissue, we quantified the entire gonad of 10 mussels of variable size. We repeatedly removed $\sim 40 \mathrm{mg}$ samples of gonad tissue with tweezers, and pressed individual samples gently between two glass microscope slides to create a squash $\sim 10 \mathrm{~mm}$ in diameter. Although this method describes the technique for bivalves, this could equally be applied to the isolated gonad of any mollusc. We repeated this until there was no more gonad tissue left in the visceral mass. We inspected each glass microscope slide thoroughly at 40× magnification using a GXM-L3200 compound microscope. Where present, we captured photos of trematode material in .tif format using a HiChrome-S camera attached to the microscope and software GX Capture 8.5 (loaded on a standard Windows PC). Each photograph captured an area of $1630 \times$ $917 \mu \mathrm{m}$. We took three photographs for each squash (i.e. a single $40 \mathrm{mg}$ sample), resulting in $n$ photographs ( $n$ ranged between 18 and 48 , depending on the size of the mussel).

Based on the extensive dissections and subsampling of the 10 mussels we concluded that assessing 12 photographs from an individual mussel generally provided reliable data on infestation levels (see Sections 'Results' and 'Discussion'). Therefore, for all other mussels, we removed four replicate samples of gonad tissue with tweezers ( $\sim 40 \mathrm{mg}$ each), and took three photos per sample from a random point in the squash. We took each sample from a different area of the gonad, namely the dorsal and ventral areas on each side of the slice. We loaded each .tif image into ImageJ 2.0.0, and carefully traced around the digenean tissue (sporocysts and cercariae) using the 'Freehand selection' tracing tool. Using the 'Measure' function in ImageJ, we calculated the total area of each trace, and hence the percentage of the photo that contained trematode material (Fig. 1). We averaged this value over all 12 replicate photos, to give the mean percentage of infected gonad for each mussel. This procedure was performed for all mussels to confirm the method's appropriateness throughout the year, when the proportion of sporocysts and cercariae may change.

\section{Statistical analysis}

All statistical analyses were executed in R v3.5.1 (R Core Team, 2018). To confirm that a subsample of the gonad approximated the true percentage of the gonad filled with trematode tissue, we analysed the 10 mussels that had their entire gonad quantified (using $n$ photographs) in the following fashion. We calculated the percentage of the gonad filled with trematode for each photo, averaged all photos to the give the true mean percentage of gonad filled for each mussel and then calculated an associated $99 \%$ confidence interval. Subsequently for each mussel, we took a random subsample of photographs without replacement (beginning with two photographs, then three, up to $n$ photographs), and calculated the mean percentage of photo filled with trematode. We repeated this procedure 1000 times for each number of photographs, and calculated the proportion of those replicates which had the estimated mean falling inside the $99 \%$ confidence interval 


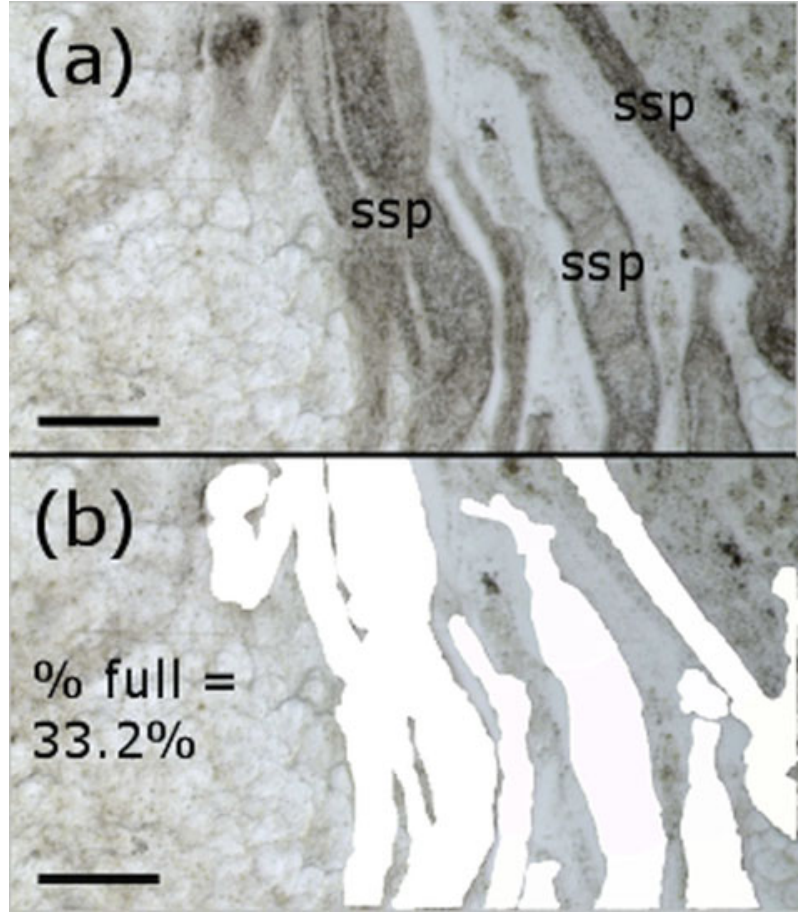

Fig. 1. Tracing and measuring procedure for a single photograph. Scale bars $=250$ $\mu \mathrm{m}$. (a) An example photo, showing spent sporocysts (ssp). (b) The traced sporocysts and their cumulative area (white), with the corresponding percentage of picture filled with sporocyst.

of the true mean. To understand how this was affected by mussel size, we compared the number of photographs required to have $90 \%$ of replicates approximating the true mean with the length of the mussel using linear regression. We checked and confirmed assumptions of linearity, normality and homoscedasticity of residuals using $Q-Q$ and residuals vs predicted values plots.

\section{Results}

Overall, trematode infections of varying intensity were observed in 72 mussels (17.1\% of all mussels examined), based on the inspections of the squashes from the gonad dissections (min: $0.2 \%$ of gonad filled with trematode tissue; max: 78.1\%). Photographs of these squashes produced high-quality images throughout the year that were used to calculate the percentage area of the gonad filled with trematode tissue, and accurately characterize the developmental stages of trematode infection (Fig. 2).

The amount of trematode tissue present varied between photographs, and shows the utility of replication of photographs for a single mussel. Additionally, as the number of photographs increased, success at estimating the true mean increased rapidly (Fig. 3). Figure 3a shows that the number of photographs required to reliably estimate the true mean is dependent on the size of the mussel, with smaller mussels approaching the true mean faster. This trend is confirmed by Fig. $3 \mathrm{~b}$, which demonstrates the significance of this relationship $\left(R^{2}=0.67, P=0.004\right)$. However, all mussels had at least $90 \%$ of replications approximating the true mean after 15 photographs (Fig. 3b), and Fig. 3 suggests that for the mean mussel size in this study $(65 \mathrm{~mm}), 10$ photographs are appropriate to estimate the true mean.

\section{Discussion}

\section{Recommendations}

A gonad squash technique has been described for the quantitative assessment of trematode infection in bivalve gonads. This method is fast and simple to use, and provides clear evidence for the presence of trematode infection, in addition to the developmental stage of the trematodes (Fig. 2). Furthermore, we have demonstrated that small sub-samples of the gonad rapidly capture the pattern in the whole gonad (Fig. 3). We therefore recommend that:

(1) the number of photographs taken is determined by the size of the bivalve;

(2) the developmental stage of the trematode is reported in addition to the infection intensity;

(3) the photographs are stored in an appropriate digital repository;

(4) future studies of parasitic castration in bivalves utilize this method to quantitatively assess infection.

The rationale behind these recommendations is briefly discussed below.

\section{Assessing method success}

There is a high level of variation evident between photographs within a single mussel. However, variation is not unexpected, given the previously observed uneven distribution of trematode infection within bivalve gonads (Taskinen et al., 1997). However, Fig. 3 shows that for an average mussel $65 \mathrm{~mm}$ long, 10 photographs will reliably estimate the true mean percentage of the gonad filled with trematode tissue. To balance time considerations against predictive power, we have recommended basing the number of photographs on the size of the bivalve, but we note that for all except for the largest mussels, a conservative 12 photographs may be an appropriate number to analyse, as this linear relationship could vary between species. Although there may still be variation present around estimates, the presented method represents a significant improvement on current quantitative efforts, where intensity is generally classed into a maximum of three categories (e.g. 'low', 'medium' and 'high'). This technique has an additional advantage in that it is reproducible, assessable by other researchers (e.g. photos can be made publicly available for inspection) and therefore can be used to compare infection prevalence and intensity across multiple studies executed by a diverse range of researchers.

We consider our method to stand up favourably to alternative procedures. Histological examination of gonadal cross-sections has been used to determine the intensity of infection in bivalvetrematode systems (e.g. Lajtner et al., 2008; Ceuta and Boehs, 2012). However, we see cross-sections as problematic. As histology uses very thin cross-sections, the resulting image for analysis is reliant on the orientation of the sporocyst in the plane that the section was taken. A transverse section of sporocyst would give a very low area, whereas a longitudinal section would give a very large area, even though both represent a single sporocyst. Our technique, which takes 3D samples and then gently compresses them, provides a more natural approximation of how much of the gonad is represented by trematode tissue. In addition, it is a lot less labour-intensive than histology, which requires setting of material in paraffin, sectioning and staining (Laruelle et al., 2002). In contrast, our technique can produce images within $5 \mathrm{~min}$ of the mussel being dissected, ready to be analysed at the researcher's convenience, thus increasing efficiency. Estimating the proportion of mollusc biomass contributed by trematodes has also been used to quantify infection, by separating host and parasite tissue (e.g. Preston et al., 2013). However, it can be very difficult to separate host and parasite tissue (Kuris et al., 2008), leading to estimates of parasite mass based on crosssections of host tissue (e.g. Hechinger et al., 2008), a method that 


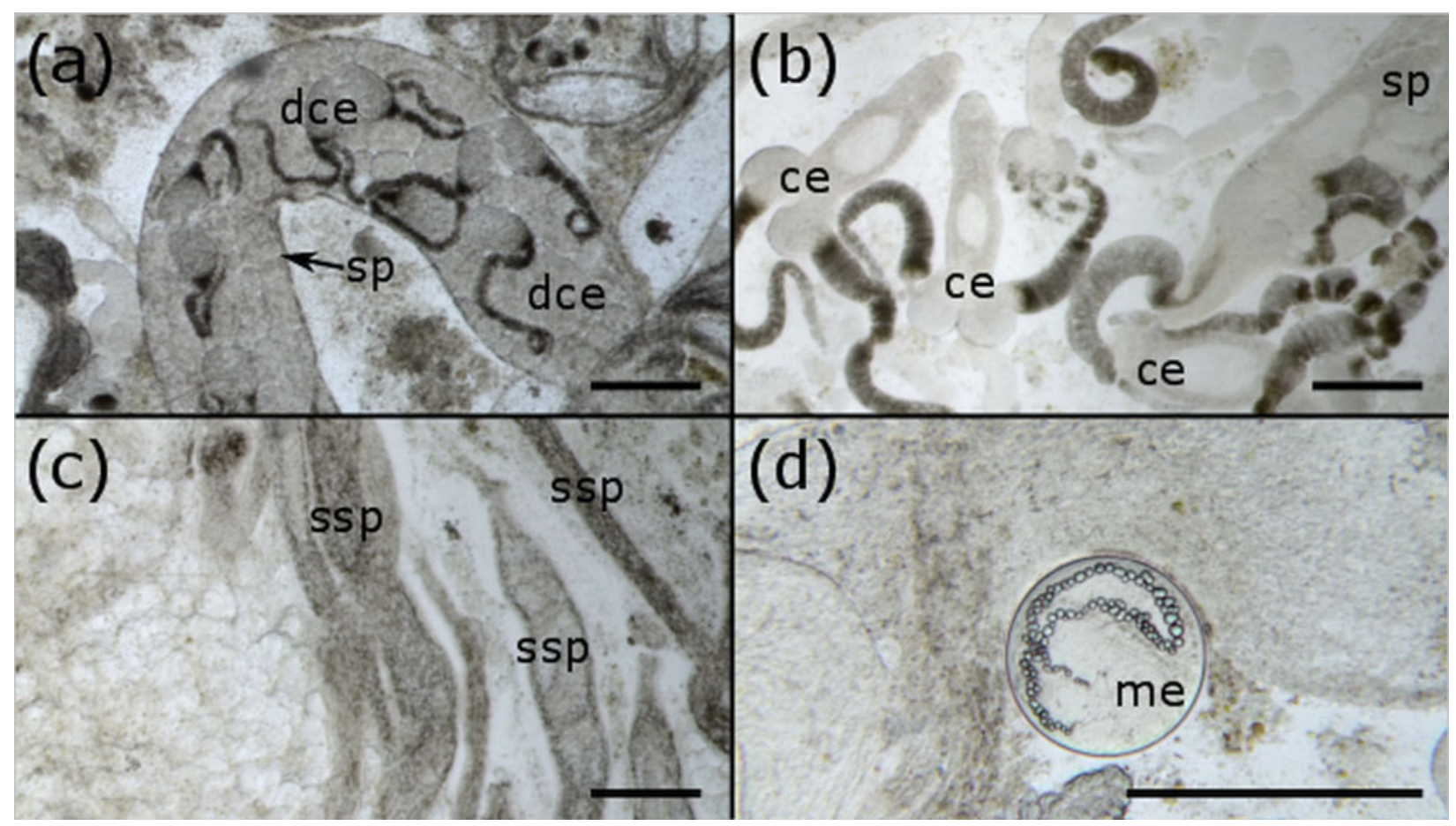

Fig. 2. Different developmental stages of digenean trematodes occupying $A$. anatina, as captured by photography. All scale bars $=250 \mu \mathrm{m}$. (a) Full sporocyst (sp) with developing cercariae (dce) inside. (b) Free cercariae (ce), ready to be released and infect a second intermediate host. (c) 'Spent' sporocysts (ssp), having released their cercariae. (d) Metacercariae (me) of echinostomatid trematodes were also occasionally observed, utilizing the mussel as a second intermediate host. Small bubbles within the metacercaria are excretory vacuoles.
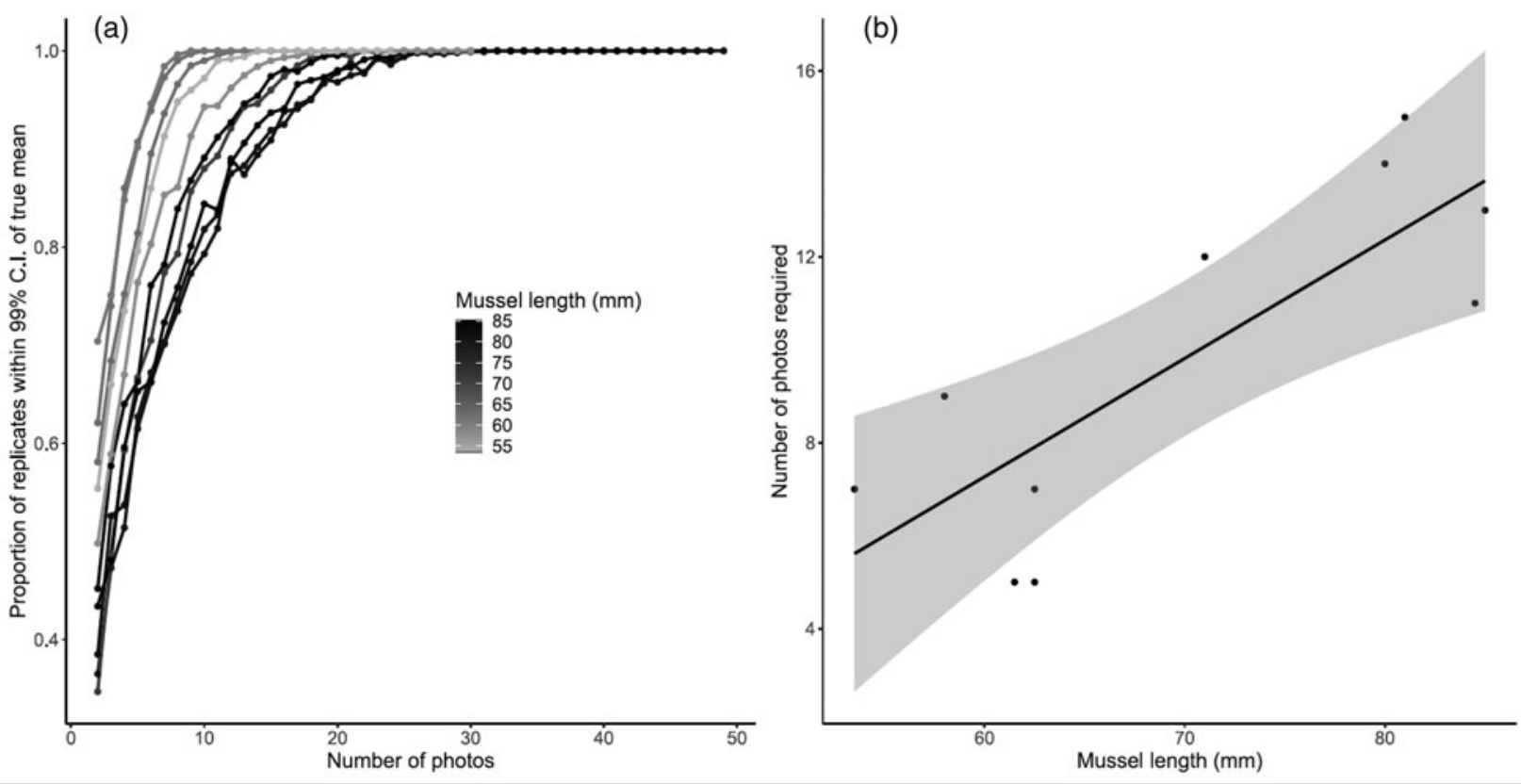

Fig. 3. Accuracy of the method for mussels of variable size. (a) Relationship between the number of photographs taken (each point represents 1000 random samples of that number of photographs, from the pool of all possible photographs), and the proportion of those 1000 replicates where the estimated mean trematode percentage fell within the $99 \%$ confidence interval of the true mean trematode percentage. Each mussel $(n=10)$ is plotted separately, and shaded according to its length in $\mathrm{mm}$. (b) Linear regression between the length of the mussel, and the number of photos required to have $90 \%$ of the replicates approximating the true mean. Shading denotes the $95 \%$ confidence interval of the fitted line.

has the potential to result in similar errors to those associated with histology. In addition, weighing such light quantities can be a long and complex procedure (e.g. see Lambden and Johnson, 2013). Therefore, the method presented here represents a simpler procedure with at least as much accuracy. There is the potential for the analysis of photographs to be further automated, through the training of computer algorithms to recognize sporocyst tissue. Automation was met with difficulties in the current study (see Fig. S1 and associated discussion in Supplementary material), but provides a potential avenue for future development.

\section{Utility of the technique in improving parasite studies}

Future studies investigating the effect of parasitism on bivalves could benefit from the method presented in this paper. 
Currently, when the effect of parasitism on a quantitative variable (e.g. gene expression, phenoloxidase activity or host fecundity) are explored, parasitic state is often defined simply as 'parasitized' or 'unparasitized' (e.g. Valderrama et al., 2004; Baudrimont et al., 2006; Magalhães et al., 2017). This approach does not accord with evolutionary theory which predicts that at initial infection and low parasite intensity, hosts may invest heavily in reproduction and defence, whereas at high intensity they will direct resources elsewhere (Hurd, 2001; Lafferty and Kuris, 2009). In short, a bivalve that is uninfected and a bivalve that has 5\% of their gonad filled are likely to be more physiologically similar compared to two infected bivalves that have 5 and $95 \%$ of their gonad filled, respectively. This point is also supported by experimental data and field observations (Sorensen and Minchella, 2001; Munoz et al., 2006). However, studies that explicitly quantify the effect of infection intensity on host or parasite dynamics are rare, and methods like the one presented in this paper should be used wherever possible. Nonetheless, it is erroneous to treat parasitism as a binary variable, as infection intensity instead represents a continuum, with variable host responses predicted along it (Kabat, 1986). In general, increased parasitic intensity may lead to increased host mortality (Mouritsen and Poulin, 2002), making its characterization crucial to understand the outcomes of parasitism for both individual hosts and host populations. The technique described in this paper provides a simple way of assessing the level of infection, not just whether it is present or not, and therefore facilitates a more nuanced characterization of host responses to parasite infection. In addition, the clear ability of the method to distinguish between developmental stages of the trematode should be taken advantage of to understand parasite development both within and between host individuals.

In summary, the method presented facilitates the rapid and realistic quantification of trematode infection in bivalve gonads. Given the important ecological role of bivalves, their conservation status and their potential as a model host-parasite system, we strongly advocate for the use of this technique to enhance biological understanding in future observational or experimental studies.

Supplementary material. The supplementary material for this article can be found at https://doi.org/10.1017/S0031182020001213.

Acknowledgements. We thank Miriam Shovel for laboratory assistance, Arlie McCarthy for useful discussions in R, Sebastian Dunne and Christine Ellis for testing the method and Prof Jouni Taskinen (University of Jyväskylä) for confirming parasite identification. In addition, we thank two anonymous reviewers, whose thoughtful comments significantly improved the quality of this manuscript.

Financial support. JIB was supported by a Woolf Fisher Scholarship, and DCA by a Dawson Fellowship from St Catharine's College, Cambridge.

Conflict of interest. None.

Ethical statement. Not applicable.

\section{References}

Aldridge DC, Fayle TM and Jackson N (2007) Freshwater mussel abundance predicts biodiversity in UK lowland rivers. Aquatic Conservation 17, 554-564.

Atkinson CL and Vaughn CC (2015) Biogeochemical hotspots: temporal and spatial scaling of the impact of freshwater mussels on ecosystem function. Freshwater Biology 60, 563-574.

Atkinson CL, Opsahl SP, Covich AP, Golladay SW and Conner LM (2010) Stable isotopic signatures, tissue stoichiometry, and nutrient cycling (C and N) of native and invasive freshwater bivalves. Journal of the North American Benthological Society 29, 496-505.
Averbuj A and Cremonte F (2010) Parasitic castration of Buccinanops cochlidium (Gastropoda: Nassariidae) caused by a lepocreadiid digenean in San José Gulf, Argentina. Journal of Helminthology 84, 381-389.

Baudoin M (1975) Host castration as a parasitic strategy. Evolution 29, 335-352.

Baudrimont M, de Montaudouin X and Palvadeau A (2006) Impact of digenean parasite infection on metallothionein synthesis by the cockle (Cerastoderma edule): a multivariate field monitoring. Marine Pollution Bulletin 52, 494-502.

Bogan AE (1993) Freshwater bivalve extinctions (Mollusca: Unionoida): a search for causes. American Zoologist 33, 599-609.

Borthagaray AI and Carranza A (2007) Mussels as ecosystem engineers: their contribution to species richness in a rocky littoral community. Acta Oecologia 31, 243-250.

Brian JI and Aldridge DC (2019) Endosymbionts: an overlooked threat in the conservation of freshwater mussels? Biological Conservation 237, 155-165.

Ceuta LO and Boehs G (2012) Parasites of the mangrove mussel Mytella guyanensis (Bivalvia: Mytilidae) in Camamu Bay, Bahia, Brazil. Brazilian Journal of Biology 72, 421-427.

Choubisa SL and Sheikh Z (2013) Parasitic castration in freshwater snail Melanoides tuberculatus (Mollusca: Gastropoda). Proceedings of the National Academy of Sciences, India, Section B: Biological Sciences 83, 193-197.

Chowdhury GW, Zieritz A and Aldridge DC (2016) Ecosystem engineering by mussels supports biodiversity and water clarity in a heavily polluted lake in Dhaka, Bangladesh. Freshwater Science 35, 188-199.

Fredensborg BL, Mouritsen KN and Poulin R (2005) Impact of trematodes on host survival and population density in the intertidal gastropod Zeacumantus subcarinatus. Marine Ecology Progress Series 290, 109-117.

Hay KB, Fredensborg BL and Poulin R (2005) Trematode-induced alterations in shell shape of the mud snail Zeacumantus subcarinatus (Prosobranchia: Batillariidae). Journal of the Marine Biological Association of the United Kingdom 85, 989-992.

Hechinger RF, Lafferty KD and Kuris AM (2008) Diversity increases biomass production for trematode parasites in snails. Proceedings of the Royal Society B: Biological Sciences 275, 2707-2714.

Hurd H (2001) Host fecundity reduction: a strategy for damage limitation? Trends in Parasitology 17, 363-368.

Jobling S and Tyler CR (2003) Endocrine disruption, parasites and pollutants in wild freshwater fish. Parasitology 126(Suppl.), S103-S108.

Kabat AR (1986) Effects of trematode parasitism on reproductive output of the bivalve Transennella tantilla. Canadian Journal of Zoology 64, 267-270.

Kuris AM, Hechinger RF, Shaw JC, Whitney KL, Aguirre-Macedo L, Boch CA, Dobson AP, Dunham EJ, Fredensborg BL, Huspeni TC, Lorda J, Mababa L, Mancini FT, Mora AB, Pickering M, Talhouk NL, Torchin ME and Lafferty KD (2008) Ecosystem energetic implications of parasite and free-living biomass in three estuaries. Nature 454, 515-518.

Lafferty KD and Kuris AM (2009) Parasitic castration: the evolution and ecology of body snatchers. Trends in Parasitology 25, 564-572.

Lajtner J, Lucić A, Marušić M and Erben R (2008) The effects of the trematode Bucephalus polymorphus on the reproductive cycle of the zebra mussel Dreissena polymorpha in the Drava River. Acta Parasitologia 53, 85-92.

Lambden J and Johnson PT (2013) Quantifying the biomass of parasites to understand their role in aquatic communities. Ecology and Evolution 3, 2310-2321.

Laruelle F, Molloy DP and Roitman VA (2002) Histological analysis of trematodes in Dreissena polymorpha: their location, pathogenicity, and distinguishing morphological characteristics. Journal of Parasitology 88, 856-863.

Lopes-Lima M, Sousa R, Geist J, Aldridge DC, Araujo R, Bergengren J, Bespalaya Y, Bódis E, Burlakova L, van Damme D, Douda K, Froufe E, Georgiev D, Gumpinger C, Karatayev A, Kebapçi Ü, Killeen I, Lajtner J, Larsen BM, Lauceri $R$, Legakis A, Lois $S$, Lundberg $S$, Moorkens E, Motte G, Nagel K-O, Ondina P, Outeiro A, Paunovic M, Prié V, von Proschwitz T, Riccardi N, Rudzite M, Rudzitis M, Scheder C, Seddon M, Şereflişan H, Simić V, Sokolova S, Stoeckl K, Taskinen J, Teixeira A, Thielen F, Trichkova $T$, Varandas $S$, Vicentini $H$, Zajac K, Zajac T and Zogaris S (2017) Conservation status of freshwater mussels in Europe: state of the art and future challenges. Biological Reviews 92, 572-607.

Lopes-Lima M, Burlakova LE, Karatayev AY, Mehler K, Seddon M and Sousa R (2018) Conservation of freshwater bivalves at the global scale: diversity, threats and research needs. Hydrobiologia 810, 1-14. 
Magalhães L, de Montaudouin X, Freitas R, Daffe G, Figueira E and Gonzalez P (2017) Seasonal variation of transcriptomic and biochemical parameters of cockles (Cerastoderma edule) related to their infection by trematode parasites. Journal of Invertebrate Pathology 148, 73-80.

Marszewska A and Cichy A (2015) Unionid clams and the zebra mussels on their shells (Bivalvia: Unionidae, Dreissenidae) as hosts for trematodes in lakes of the Polish lowland. Folia Malacologica 23, 149-154.

Mouritsen KN and Poulin R (2002) Parasitism, community structure and biodiversity in intertidal ecosystems. Parasitology 124, 101-117.

Munoz P, Meseguer J and Esteban MA (2006) Phenoloxidase activity in three commercial bivalve species. Changes due to natural infestation with Perkinsus atlanticus. Fish and Shellfish Immunology 20, 12-19.

Ninokawa A, Takeshita Y, Jellison BM, Jurgens LJ and Gaylord B (2020) Biological modification of seawater chemistry by an ecosystem engineer, the California mussel, Mytilus californianus. Limnology and Oceanography 65, 157-172.

Preston DL, Orlofske SA, Lambden JP and Johnson PT (2013) Biomass and productivity of trematode parasites in pond ecosystems. Journal of Animal Ecology 82, 509-517.

R Core Team (2018) R: A Language and Environment for Statistical Computing. Vienna, Austria: R Foundation for Statistical Computing.

Smith JR, Fong P and Ambrose RF (2006) Dramatic declines in mussel bed community diversity: response to climate change? Ecology 87, 1153-1161.

Sorensen RE and Minchella DJ (2001) Snail-trematode life history interactions: past trends and future directions. Parasitology 123(Suppl.), S3-S18.

Sousa R, Gutierrez JL and Aldridge DC (2009) Non-indigenous invasive bivalves as ecosystem engineers. Biological Invasions 11, 2367-2385.
Taskinen J and Valtonen ET (1995) Age-, size-, and sex-specific infection of Anodonta piscinalis (=anatina) (Bivalvia: Unionidae) with Rhipidocotyle fennica (Digenea: Bucephalidae) and its influence on host reproduction. Canadian Journal of Zoology 73, 887-897.

Taskinen J, Valtonen ET and Mäkelä T (1994) Quantity of sporocysts and seasonally of two Rhipidocotyle species (Digenea: Bucephalidae) in Anodonta piscinalis (Mollusca: Bivalvia). International Journal for Parasitology 24, 877-886.

Taskinen J, Mäkelä T and Valtonen ET (1997) Exploitation of Anodonta piscinalis (Bivalvia) by trematodes: Parasite tactics and host longevity. Annales Zoologici Fennici 34, 37-46.

Thieltges DW, de Montaudouin X, Fredensborg B, Jensen KT, Koprivnikar J and Poulin R (2008) Production of marine trematode cercariae: a potentially overlooked path of energy flow in benthic systems. Marine Ecology Progress Series 372, 147-155.

Valderrama K, Oliva M, Campos B and Brown D (2004) Parasitic castration of Eurhomalea lenticularis (Bivalvia: Veneridae) by a digenetic trematode: quantitative histological analysis. Diseases of Aquatic Organisms 59, 151-158.

Yanovich LM (2015) Reproductive features of indigenous and the invasive Chinese freshwater mussels (Mollusca, Bivalvia, Anodontinae) in Ukraine. Vestnik Zoologii 49, 433-438.

Yee-Duarte JA, Ceballos-Vázquez BP, Shumilin E, Kidd KA and Arellano-Martínez M (2017) Parasitic castration of chocolate clam Megapitaria squalida (Sowerby, 1835) caused by trematode larvae. Journal of Shellfish Research 36, 593-599.

Zieritz A and Aldridge DC (2011) Sexual, habitat-constrained and parasite-induced dimorphism in the shell of a freshwater mussel (Anodonta anatina, Unionidae). Journal of Morphology 272, 1365-1375. 